\title{
ALIMENTARY MODELS OF THE ETHNIC OTHER IN THE (POST-)COVID PERIOD
}

\section{Rastyam T. Aliev (a), Olesya S. Yakushenkova ${ }^{2}$ (a)}

(a) Astrakhan State University. Astrakhan, Russia

\begin{abstract}
This article analyzes the post-Covid image of the Other in the gastronomic aspect. The research is a continuation of complex studies on the construction of models of the Otherness and identification of alerting markers in the modern Internet space. The authors rely on the assumption that food culture is a basic characteristic, through which both self-identification and the definition of Otherness take place. From the researchers' point of view, the Other in the alimentary aspect appears as a subject whose food system is as extraordinary as possible in terms of "our" cultural patterns, which allows, according to the authors, to identify indicators of latent fear of the Other. By actualizing their curiosity about the Otherness through Internet queries, the subjects thereby signify their interest in obtaining additional information about the Other and their everyday practices.

In this study, the authors, on the basis of the revealed internet queries, carry out an analysis of the typical markers of alimentary Otherness in the post-Covid period. The findings of this research allow the authors to compare the identified patterns with those that had been got in the pre-Covid period. It is noted that the fear of OtherCannibal, almost absent in the 2019 analysis, has gained new actualisation in the Asian cluster of models based on the analysis of data for the 2020-2021 period. There is also a general actualisation of the alimentary component of the Otherness, caused, according to the authors, by the pandemic.
\end{abstract}

\section{Keywords}

The Other; Otherness; Patterns of Otherness; food culture; Covid; Post-Covid; Gastronomic Culture; Model; Model construction; Correlation

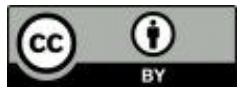

This work is licensed under a Creative Commons «Attribution» 4.0 International License

1 Email: rastaliev[at]gmail.com

2 Email: jestershadow[at]mail.ru 


\title{
АЛИМЕНТАРНЫЕ МОДЕЛИ ЭТНИЧЕСКОГО ЧУЖОГО В (ПОСТ)КОВИДНЫЙ ПЕРИОД
}

\author{
Алиев Растям Туктарович ${ }^{1}(\mathrm{a})$, Якушенкова Олеся Сергеевна ${ }^{2}$ (a) \\ (а) Астраханский государственный университет. Астрахань, Россия
}

\section{Аннотация}

Данная статья посвящена анализу постковидного образа Чужого в его алиментарном аспекте. Исследование является продолжением комплексной работы по построению моделей образа Чужого и выявления алертных маркеров в современном интернет-пространстве. Авторы исходят из положения, что алиментарная культура является одной из базовых характеристик, с помощью которых происходит как самоидентификация, так и дефиниция Инаковости. С точки зрения исследователей, Чужой в алиментарном аспекте предстаёт как субъект, чья гастрономическая система является максимально нестандартной с точки зрения «наших» культурных паттернов, что позволяет, по мнению авторов, выявлять индикаторы скрытого страха перед Чужим. Актуализируя свое любопытство по отношению к инаковости Чужого с помощью интернет запросов, субъект тем самым обозначает свою заинтересованность в получении дополнительной информации о Чужом и его повседневных практиках.

В своем исследовании авторы, на основе выявленных интернет запросов, проводят анализ типичных для постковидного периода маркеров алиментарной Инаковости. Полученные в ходе исследования результаты позволили авторам сравнить выявленные модели с моделями, которые были актуальны в доковидный период. Отмечается, что страх перед Чужим-каннибалом, практически отсутствующий в анализе 2019 года, получил новую актуализацию в азиатском кластере моделей, построенных на анализе данных за в 2020-2021 гг. Наблюдается также общая актуализация алиментарной составляющей моделей Чужого, причиной чего, по мнению авторов становится пандемия.

\section{Ключевые слова}

Чужой; Инаковость; паттерны инаковости; алиментарность; ковидный период; постковидный период; гастрономическая культура; модель; моделирование; корреляция

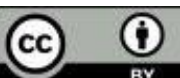

Это произведение доступно по лицензии Creative Commons «Attribution» («Атрибуция») 4.0 Всемирная

1 Email: rastaliev[at]gmail.com

2 Email: jestershadow[at]mail.ru 


\section{ВВЕДЕНИЕ}

Будучи актуальной во все времена, проблема Другого/Чужого в современном постиндустриальном мире даёт новые возможности более глубокого исследования межкультурной коммуникации в междисциплинарном контексте. Инаковость возникает на границе гносеологических и онтологических феноменов, что позволяет Чужому выступать в различных ролях в межкультурном взаимодействии: от посредника коммуникации до некоего маркера состояния той или иной культуры или общества. Последнее, в свою очередь, даёт возможность «намечать те “лекарства", которые этому обществу требуются» (Якушенков, 2012b, с. 264). Эта функция важна для исследователей потому, что раскрывает определённые проблемы социума, актуальные для того или иного этапа его развития. Сам же образ Чужого чрезвычайно актуализируется в периоды кризисных явлений, связанных как с социальными потрясениями, так и с ситуациями природного характера. Недавние события в мире показали, насколько современное общество не готово к последним: пандемия коронавируса охватила всё земное сообщество, все государства маленькой планеты Земля столкнулись с практическим бессилием перед бедой такого рода. И хотя человечество начало уже находить выход из кризиса (путём создания различных вакцин), сам факт существования подобной угрозы не прошел мимо всех сфер жизни человека. Именно в такое время Чужой и трансформируется, превращаясь во всё новые феномены и явления.

Но если Чужой так важен для исследователей, то как его определить? Как выявить те аспекты, маркеры, которые он транслирует и благодаря которым он конструируется? В основе данного исследования лежит концепция трёхчленной структуры инаковости, разработанная антропологом С. Н. Якушенковым, который в своих исследованиях телесности варваров на фронтирных территориях Китая заметил:

\footnotetext{
«важными аспектами конструирования образа Чужого в пограничных областях у разных народов являются <...> вестиментарные и алиментарные предпочтения представителей других национальностей, воспринимаемых в качестве Чужих, их сексуальные предпочтения или традиции, или даже навязывание им оных и т.д. Из наиболее значимых можно назвать следующие признаки: внешность, еда, секс» (Якушенков \& Якушенкова, 2012, с. 234).
}

Целью данной статьи является моделирование алиментарного образа этнического Чужого на основе поисковых запросов россиян 
в ковидный период (2020-2021 гг.). Эта цель вытекает из гипотезы о том, что пандемия потрясла мир настолько, что определение нового образа этнического Чужого в этих условиях помогло бы проследить трансформацию в сравнении с доковидным периодом, выявить основные закономерности этой трансформации и проанализировать точки бифуркации российского общества в кризисный момент. Само исследование является комплексным и содержит в себе только одну из трёх категорий. При этом алиментарность, на наш взгляд, является самой важной из их. Не зря она вместе с сексуальностью (пусть и в иной форме, как жажда, голод и половое влечение) лежит в основе пирамиды Маслоу (Maslow, 1943). Отсюда и рождается базовый (первобытный) страх человека перед Чужим, который в плоскости Воображаемого является угрозой, способной лишить субъекта основы жизни (например, пищи). При этом Чужой в алиментарном аспекте предстаёт как объект, питающийся нестандартной для «нашей» культуры едой.

В контексте комплексного исследования в 2018 году мы опубликовали первые результаты работы. Тогда мы проанализировали предмет нашего исследования сквозь призму алиментарной (гастрономической) культуры. В 2019 году вновь было проведено подобное исследование (Алиев \& Якушенкова, 2019, рр. 72-93) показавшее, что образы Чужого изменились: некоторые маркеры для его обозначения стали более актуальными, другие потеряли своё значение, что повлекло за собой изменение общей картины. А анализ сегодняшнего состояния видения Чужого даст нам новые данные для дальнейшего анализа нашего общества.

Перед тем, как описать методы и полученные результаты, мы бы хотели акцентировать внимание на том, что не разделяем оценочные суждения по отношению к другим этническим группам, которые могут быть восприняты оскорбительно, уничижительно или агрессивно. Все указанные в дальнейшем маркеры, содержащие подобную характеристику, исследуются нами лишь в научных целях, чтобы выявить степень алертности по отношению к определённым моделям инаковости, и не пропагандируют призывы к насилию и оскорбления на национальной почве.

\section{СТЕПЕНЬ РАЗРАБОТАННОСТИ ПРОБЛЕМЫ}

Прежде всего необходимо подчеркнуть, что к самому феномену Чужого посвятили свои работы различные исследователи. Их разнообразие велико в контексте междисциплинарности предмета исследо- 


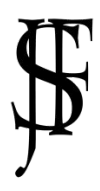

вания. Сама проблема Чужого поднимается с античных времён (Вальденфельс, 2002).

Опыта Чужого и его моделирование явилось стартовой точкой в феноменологии. Это можно проследить в творчестве Э. Гуссерля (2001), Э. Левинаса (2007), Ж.-П. Сартра (2000). Особый вклад в этой области внёс Б. Вальденфельс, который разработал «респонзивную» модель Чужого (1999, сс. 130-131). Телесность Другого была одной и центральной тем творчества М. М. Бахтина (1979).

Особо к образам инаковости обращается в своих работах французский философ М. Фуко. В них он видел политический аспект, а само значение фигуры Другого он связывал с конструированием европейской рациональности (1997).

В современных зарубежных исследованиях Чужой является чрезвычайно актуальным. И. Б. Ньюман (Neumann, 1998) рассматривает образ Чужого как ведущий фактор формирования социального и политического идентичностей. С исторической позиции актуальность Чужого в Античности рассматривает в своих трудах Э. С. Груэн (Gruen, 2011). Некоторые зарубежные исследователи посвящают свои работы исследованиям монструозных образов в истории, политике и культуре (Cohen, 1996). Историческая ретроспектива высматривается в работах Н. Беренда, К. Мюллера и их коллег, которые выявляют роль этнического Другого в конструировании идентичности (Buc, Keil, \& Tolan, 2016). В Росии среди исследователей инаковости необходимо отметить Л. И. Гришаеву (2003), А. С. Корчака (2006), А. В. Шипилова (2008) и других.

Исследования алиментарной культуры рассматриваются сегодня в различных работах с разных сторон. Так, например, специалист в семиотике современной гастрономической культуры Ф. Парасеколи утверждает: «Пища является одновременно важным источником значения и эффективной формой общения, основанной на ограниченном, хотя и очень широком, разнообразии пищевых веществ, практик, убеждений и норм, которые образуют сеть взаимосвязанных систем... Когда различные кулинарные семиосферы взаимодействуют, опыт, связанный с едой, раскрывает культурный характер гастрономических компетенций, вынуждая людей взаимодействовать с Чужим посредством воплощенного общения» (Parasecoli, 2011, p. 645). Ряд исследователей обращается к анализу гастрономической культуры колониальных и постколониальных государств и рассматривает вопросы её изменения под влиянием алиментарности Чужого (Ray, 2015). Рассматривая гастрономический туризм как современное явление, другие исследователи под влиянием теории различий 
П. Бурдье разработали модель, которая фиксирует переходы в габитусе. «Эта модель может быть применена к любому культурному контексту в индустрии туризма, чтобы обеспечить влияние конкурирующих вкусовых процессов» (Stringfellow, MacLaren, Maclean, \& O’Gorman, 2013, p. 77).

Таким образом мы можем наблюдать большой интерес к объекту и предмету нашего исследования у широких кругов исследователей различной дисциплинарной направленности. Это ещё раз подчёркивает актуальность поднимаемой нами проблемы, в которую мы хотели бы внести прикладной характер.

\section{МЕТОДОЛОГИЯ И МЕТОДЫ}

Методологической основой данной работы стала трехчленная структура образа Чужого, разработанная российским ученым С. Н. Якушенковым. Она включает в себя алиментарность, вестиментарность (внешний облик) и сексуальность (Якушенков, 2012а). В данной работе мы также активно прибегали к семиотическим методам исследования, позволившим выявить структуру образа Чужого и проанализировать ее с позиций синтаксиса, семантики и прагматики. Здесь также необходимо упомянуть работы французского структуралиста К. Леви-Стросса, особо выделявшего в человеческой культуре пищевые коды (1999).

В качестве научных инструментариев были использованы статистические методы сбора данных в сети Интернет, составление корреляционной матрицы, расчёт корреляции по Пирсону каждой пары структурных маркеров и выявление сильнейших корреляционных связей между этими маркерами. Для конструирования, структурирования и классификации моделей Воображаемого Чужого мы использовали визуализацию корреляционных связей маркеров на плоскости, что дало возможность выделить, с одной стороны, количество моделей, а, с другой, их качественную характеристику, выраженную наполненностью моделей этими сгруппированными маркерами. Более подробно об этапах исследования мы писали в предыдущей статье (Алиев \& Якушенкова, 2019). Здесь мы опишем их кратко. Для начала мы сделали выборку этносов, которые нам были необходимы в рамках комплексного исследования. В эту выборку вошли китайцы, корейцы, японцы, французы, немцы, англичане, американцы, украинцы, казахи, армяне, азербайджанцы, грузины, таджики. Затем нам необходимо было выявить алиментарные маркеры через интернет-запросы россиян в популярном в России поисковом сервисе yandex.ru. Отметим, что эти интернет-запросы показывают, прежде 


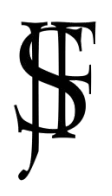

всего, массовый интерес рядовых пользователей по тому или иному вопросу. Поэтому они выдают некий общий, усреднённый признак чаще всего задаваемого запроса.

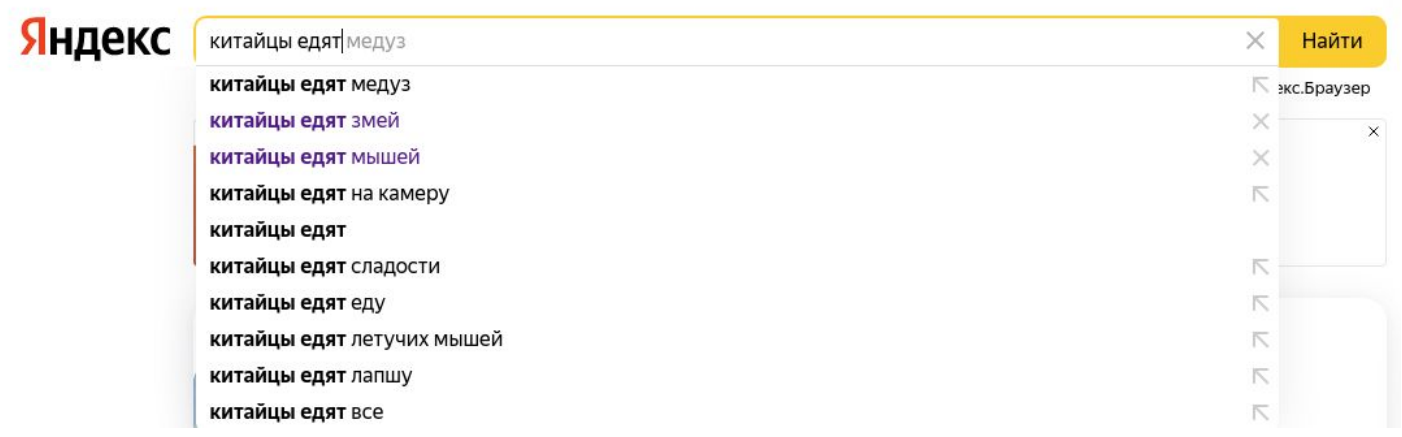

Рисунок 1. Пример формирования поисковых запросов в Яндексе

Figure 1: Example of search query generation in Yandex

\begin{tabular}{|c|c|c|c|c|c|c|c|c|c|c|c|c|c|}
\hline 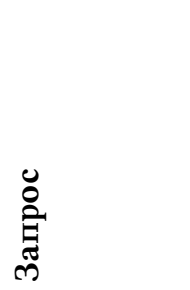 & تص & 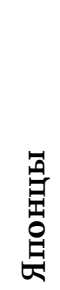 & 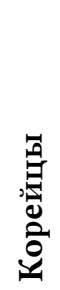 & 㿣 & 苞 & 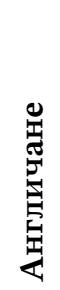 & 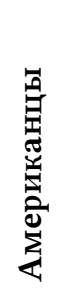 & 恶 & 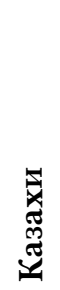 & 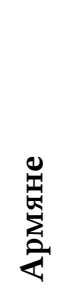 & 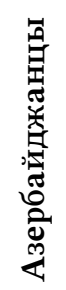 & 总 & 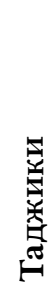 \\
\hline $\begin{array}{l}\text { Апельсино } \\
\text { вый сок }\end{array}$ & 0 & 0 & 0 & 0 & 0 & 0 & 23 & 0 & 0 & 0 & 0 & 0 & 0 \\
\hline Бешбармак & 0 & 0 & 0 & 0 & 0 & 0 & 0 & 0 & 20 & 0 & 0 & 0 & 0 \\
\hline Вино & 0 & 0 & 0 & 213 & 0 & 0 & 0 & 0 & 0 & 0 & 0 & 65 & 0 \\
\hline Водку & 260 & 24 & 0 & 0 & 35 & 0 & 145 & 0 & 0 & 0 & 0 & 0 & 25 \\
\hline Воду & 715 & 62 & 0 & 0 & 0 & 0 & 0 & 0 & 0 & 0 & 0 & 0 & 0 \\
\hline $\begin{array}{l}\text { Горячую } \\
\text { воду }\end{array}$ & 2169 & 84 & 0 & 0 & 0 & 0 & 0 & 0 & 0 & 0 & 0 & 0 & 0 \\
\hline Гречку & 0 & 0 & 0 & 0 & 0 & 0 & 117 & 0 & 0 & 0 & 0 & 0 & 0 \\
\hline Грибы & 0 & 0 & 0 & 0 & 0 & 0 & 0 & 0 & 0 & 0 & 0 & 53 & 0 \\
\hline
\end{tabular}

Таблица 1. Пример корреляционной матрицы

Table 1. Example of a correlation matrix.

На данном этапе в поисковом сервисе yandex.ru нами вводился запрос, сформированный по типу «\%еthnic_groups\% едят», где 
\%ethnic_groups\% - название этноса, например китайцы. При этом сервисы, благодаря интеллектуальной системе, предлагали выбрать продолжение запроса из списка наиболее часто встречаемых у других пользователей сети Интернет. Нами было выявлено 67 алиментарных маркеров. При этом в 2018 году мы выявили 37, а в 2019 году - 39.

Далее мы провели расчёт корреляции каждой пары выявленных нами маркеров, что дало возможность составить корреляционную таблицу (см. Таблица 2). На этом этапе нам необходимо было выделить коэффициент наисильнейшей корреляционной связи отдельных пар признаков. Для этого мы взяли диапазон коэффициента корреляции равный от 0,6 до 1, и эту связь каждой пары признаков мы визуализировали на условной карте (см. Рисунок 2), что позволило нам сгруппировать данные и выделить основные универсальные алиментарные модели воображаемого Чужого.

\begin{tabular}{|c|c|c|c|c|c|c|c|c|c|c|}
\hline & $\begin{array}{c}\text { Апель } \\
\text { синов } \\
\text { ый сок }\end{array}$ & $\begin{array}{c}\text { Бешба } \\
\text { рмак }\end{array}$ & Вино & Водку & Воду & $\begin{array}{l}\text { Горячу } \\
\text { ю воду }\end{array}$ & Гречку & Грибы & $\begin{array}{c}\text { Дельф } \\
\text { инов }\end{array}$ & Детей \\
\hline $\begin{array}{l}\text { Апель } \\
\text { синов } \\
\text { ый сок }\end{array}$ & 1 & & & & & & & & & \\
\hline $\begin{array}{l}\text { Бешба } \\
\text { рмак }\end{array}$ & $-0,083$ & 1 & & & & & & & & \\
\hline Вино & $-0,106$ & $-0,106$ & 1 & & & & & & & \\
\hline Водку & 0,414 & $-0,145$ & $-0,185$ & 1 & & & & & & \\
\hline Воду & $-0,09$ & $-0,090$ & $-0,116$ & 0,857 & 1 & & & & & \\
\hline $\begin{array}{l}\text { Горячу } \\
\text { ю воду }\end{array}$ & $-0,086$ & $-0,086$ & $-0,110$ & 0,858 & 0,998 & 1 & & & & \\
\hline Гречку & 1 & $-0,083$ & $-0,106$ & 0,4146 & $-0,09$ & $-0,086$ & 1 & & & \\
\hline Грибы & $-0,083$ & $-0,083$ & 0,217 & $-0,145$ & $-0,090$ & $-0,086$ & $-0,083$ & 1 & & \\
\hline $\begin{array}{l}\text { Дельф } \\
\text { инов }\end{array}$ & $-0,083$ & $-0,083$ & $-0,106$ & $-0,052$ & 0,0033 & $-0,044$ & $-0,083$ & $-0,083$ & 1 & \\
\hline Детей & $-0,057$ & $-0,093$ & $-0,119$ & 0,865 & 0,99 & 0,994 & $-0,057$ & $-0,093$ & $-0,093$ & 1 \\
\hline
\end{tabular}

Таблица 2. Часть корреляционной таблицы ${ }^{1}$

Table 2. Part of the correlation table

1 Полная версия таблицы и расчётов доступны по ссылке: https://docs.google.com/spreadsheets/d/1cpELXK9-eChkoRch0Gy9 sY6BiElr6cO3syBZ4AjBHc/ edit?usp=sharing 


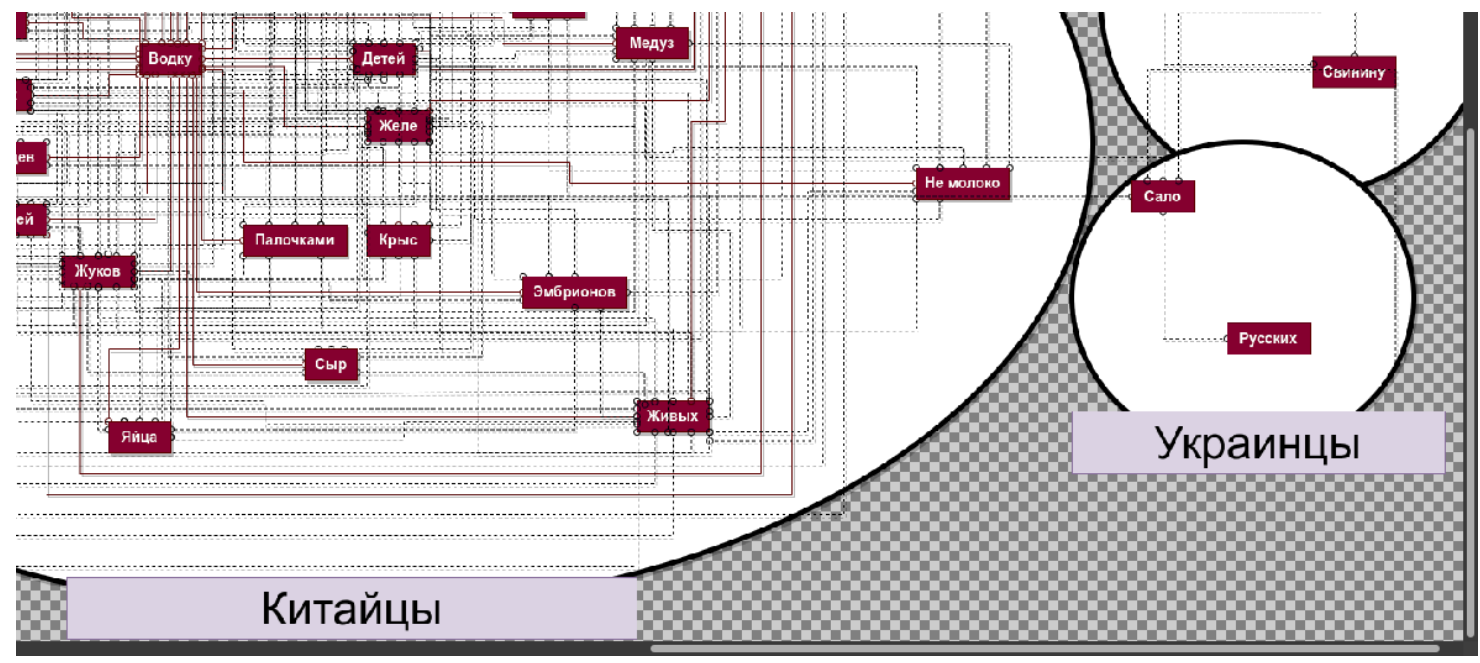

Рисунок 2. Часть карты алиментарных маркеров, сгруппированных по корреляционным связям между собой ${ }^{2}$

Figure 2: Part of the map of alimentary markers grouped by correlations between each other

\section{РЕЗУЛЬТАТЫ ИССЛЕДОВАНИЯ}

Визуализация маркеров в этом исследовании показала, что алиментарный аспект Чужого в отличие от предыдущих полученных нами ранее результатов стал конкретизироваться. Если раньше мы получали размытые модели, в которых алертность была условной, то теперь в некоторых моделях алертность модели Чужого выражается более конкретно. Мы можем только предположить, что это связано с последними мировыми событиями и пандемией в общем.

На этот раз мы получили 10 моделей Чужого, актуализирующих представление россиян о наших соседях и геополитических «партнёрах». При этом на карте выделяются три сгруппированные модели азиатского кластера - китайцы, японцы и корейцы. Самой большой в данном случае является модель «Чужой-китаец», представленная наибольшим количеством максимально алертных маркеров (такие, как «ест детей», «эмбрионов», «летучую мышь», «живых», «тараканов», других «насекомых» и т.д.). Большинство из этих маркеров связаны с каннибализмом и поеданием человеческой плоти. Например, запрос «китайцы едят живых» россияне вводили в поисковой запрос 268 раз в месяц (среднемесячные данные); запрос «китайцы едят младенцев» 236 раз; а запрос «китайцы едят детей» - 605. При этом связанные с пандемией запросы по типу «китайцы едят мышей» и «китайцы едят

2 В лучшем разрешении карту можно посмотреть по ссылке:

https://drive.google.com/file/d/1gYNKU5bJr 3X3CZ6N1nuRZtnWYcKEpd9/view?usp=sharing 
летучих мышей» россиян интересовало 1012 и 290 раз соответственно. Это говорит о настороженной заинтересованности россиян алиментарной традицией китайцев с одной стороны, и даже страхом перед Чужим-китайцем-каннибалом, с другой. Также возросший интерес россиян к теме поедания китайцами летучих мышей связан, скорее всего, с пандемией коронавируса и одной из версией появления вируса Ковид-19. Среди прочих, особо выделяются маркеры, обозначающие алиментарные пристрастия указанных этносов к странной еде: крыс, тараканов и насекомых и т.д..

Также к большому кластеру азиатских моделей инаковости мы отнесли модели «Чужого-корейца» и «Чужого-японца», которые имеют по сравнению с моделью «Чужого-китайца» меньшее количество маркеров, а их коннотация менее алертна. Так, к примеру, в их случае отмечается большой интерес россиян к наблюдению за процессом поедания: маркер «... едят на камеру», который является общим как для корейцев (1834 поисковых запроса), так и для японцев (326 поисковых запроса). При этом алертным в модели «Чужой-кореец» является маркер «едят собак» (1594 поисковых запроса россиян). В модели «Чужой -японец» явно алертных маркеров нет, хотя в стереотипах россиян имеются представления о японцах, которые едят странную еду, например, «дельфинов», но подобных запросов в месяц у россиян критически мало (всего 28 запросов).

Маленькими моделями являются модели «Чужой-казах», «Чужой-француз», «Чужой-англичанин», «Чужой-американец», «Чужой-немец», «Чужой-грузин», «Чужой-украинец». Все они имеют от 4-х до 2-х маркеров, что говорит о незначительном интересе россиян к алиментарности представленных групп. При этом условную алертную коннотацию имеют по-прежнему лишь модели американцев («едят русскую еду» - 38 запросов) и украинцев («едят русских» - 127 запросов в месяц). Это объясняется геополитическими событиями последних лет, которые и повлияли на алиментарное представление россиян об этих народах. Если в первом случае («едят русскую еду») американцы представляются как условные враги, которые могут забрать «нашу» еду, то во втором случае мы снова видим каннибалистскую коннотацию инаковости - украинцы предстают в стереотипах как убийцы и поедатели русской плоти. Но стоит снова подчеркнуть, что среднемесячное количество обращений в этом ключе слишком мало, чтобы можно было говорить о повсеместном страхе, и мы лишь фиксируем сам факт присутствия подобного маркера инаковости. 


\section{ВЫВОДЫ}

Представленное исследование направлено на выявление механизмов межкультурной коммуникации посредством алиментарности Чужого. Повторимся, что, с одной стороны, Чужой является объектом наших глубинных страхов, мечтаний и переживаний, а, с другой, Чужой и чужая культура интересуют нас. Его привычки, внешность, обычаи и традиции одновременно и пугают, и интригуют. Поэтому нет ничего удивительного в том, что у россиян проявляется интерес к тем или иным народам, а своё любопытство они пытаются удовлетворить в интернете, так как сегодня он стал универсальным инструментом поиска информации, а также каналом межкультурной коммуникации.

Если в 2019 году каннибалистические маркеры были представлены меньше, то в 2020-2021 гг. они получили новую актуализацию в азиатском кластере моделей, а также по отношению к украинцам. Более того, теперь в новых условиях (пандемия) мы говорим об актуализации алиментарной составляющей моделей Чужого, тогда как в предыдущие периоды алиментарность была размыта, и нельзя было сказать об алертности тех или иных моделей Чужого.

\section{БЛАГОДАРНОСТИ}

Работа выполнена при финансовой поддержке Совета по грантам Президента Российской Федерации для для государственной поддержки молодых российских ученых. Проект МК-66.2021.2 «Компаративистский анализ доковидных и постковидных образов Воображаемого Чужого: моделирование на основе поисковых запросов россиян в сети Интернет».

\section{Список литературы}

Buc, P., Keil, M., \& Tolan, J. (2016). Jews and Christians in Medieval Europe: The Historiographical Legacy of Bernhard Blumenkranz. Turnhout: Brepols Publishers n.v.

Cohen, J. J. (1996). Monster Theory: Reading Culture. Minneapolis: University of Minnesota Press.

Gruen, E. S. (2011). Rethinking the Other in Antiquity. Princeton: Princeton University press.

Maslow, A. H. (1943). A Theory of Human Motivation. Psychological Review, (50), 370-396. doi: $10.1037 / \mathrm{h} 0054346$

Neumann, I. B. (1998). Uses of the Other. 'The East' in European Identity Formation. Minneapolis: University of Minnesota Press. 
Parasecoli, F. (2011). Savoring Semiotics: Food in Intercultural Communication. Social Semiotics, 21(5), 645-663. doi: 10.1080/10350330.2011.578803

Ray, U. (2015). Introducing 'Foreign' Food Changes in the Gastronomic Culture of Colonial Bengal. Cambridge: Cambridge Univ Press.

Stringfellow, L., MacLaren, A., Maclean, M., \& O'Gorman, K. (2013). Conceptualizing Taste: Food, Culture and Celebrities. Tourism Management, (37), 77-85. doi: 10.1016/ j.tourman.2012.12.016

Алиев, Р. Т., \& Якушенкова, О. С. (2019). Моделируя Воображаемое в Интернете: Трансформация алиментарных моделей Чужого. Galactica Media: Fournal of Media Studies, 1(3), 72-93. doi: 10.24411/2658-7734-2019-10025

Бахтин, М. М. (1979). Эстетика словесного творчества. Москва.

Вальденфельс, Б. (1999). Мотив Чужого. Мн.

Вальденфельс, Б. (2002). Феномен Чужого и его следы в классической греческой философии. Топос, (2), 4-21.

Гришаева, Л. И. (2003). Аккультурация как трансформация оппозиции «вой»-"Чужой". Волгоград: Перемена.

Гуссерль, Э. (2001). Картезианские размышления. СПб: Наука.

Корчак, А. С. (2006). Философия Другого «Я»: История и современность. Москва: ЛЕНАНД.

Левинас, Э. (2007). Путь к Другому (Е. Бахтина, Пер.). СПб: Изд-во Санкт-Петербургского университета.

Леви-Стросс, К. (1999). Мифологики. Том 1. Сырое и приготовленное. СПб.: Университетская книга.

Сартр, Ж. П. (2000). Былте и ничто: Опьт феноменологической онтологии (В. И. Колядко, Пер.). Москва: Республика.

Фуко, М. (1997). История безумия в классическую эпоху. СПб.

Шипилов, А. В. (2008). Свой, Чужой и Другие. Москва: Прогресс-Традиция.

Якушенков, С. Н. (2012а). Образ Чужого - от деконструкции к конструкции. Каспийский регион: политика, экономика, культура, (3), 242-249.

Якушенков, С. Н. (2012b). Эволюция образа Чужого на примере европейского дискурса о вампирах (О бедном вампире замолвим мы слово). Каспийский регион: политика, экономика, культура, (23), 263-269.

Якушенков, С. Н., \& Якушенкова, О. С. (2012). Тело варвара: Конструирование образа Чужого на китайском фронтире. Каспийский регион: политика, экономика, культура, (4), 233-240. 


\section{References}

Aliev, R. T., \& Yakushenkova, O. S. (2019). Modeling the Imaginary on the Internet: Transforming of Alimentary Models of the Other. Galactica Media: Fournal of Media Studies, 1(3), 72-93. doi: 10.24411/2658-7734-2019-10025 (In Russian).

Bakhtin, M. M. (1979). The Aesthetics of Wordsmithing. Moscow. (In Russian).

Buc, P., Keil, M., \& Tolan, J. (2016). Jews and Christians in Medieval Europe: The Historiographical Legacy of Bernhard Blumenkranz. Turnhout: Brepols Publishers n.v.

Cohen, J. J. (1996). Monster Theory: Reading Culture. Minneapolis: University of Minnesota Press.

Foucault, M. (1997). Madness and Civilization: A History of Insanity in the Age of Reason. St. Petersburg. (In Russian).

Grishaeva, L. I. (2003). Acculturation as a Transformation of the Opposition "The Ourselves vs. the Others". Volgograd: Peremena. (In Russian).

Gruen, E. S. (2011). Rethinking the Other in Antiquity. Princeton: Princeton University press.

Husserl, E. (2001). Cartesian Meditations. St. Petersburg: Nauka. (In Russian).

Korchak, A. S. (2006). Philosophy of the Other Self: History and Modernity. Moscow: LENAND. (In Russian).

Lévi-Strauss, K. (1999). Mythologiques. Volume 1. Raw and cooked. St. Petersburg: University Book. (In Russian).

Levinas, E. (2007). The Way to the Other (Е. Bakhtina, Екфты.). St. Petersburg: St. Petersburg University Press. (In Russian).

Maslow, A. H. (1943). A Theory of Human Motivation. Psychological Review, (50), 370-396. doi: $10.1037 / \mathrm{h} 0054346$

Neumann, I. B. (1998). Uses of the Other. 'The East' in European Identity Formation. Minneapolis: University of Minnesota Press.

Parasecoli, F. (2011). Savoring Semiotics: Food in Intercultural Communication. Social Semiotics, 21(5), 645-663. doi: 10.1080/10350330.2011.578803

Ray, U. (2015). Introducing 'Foreign' Food Changes in the Gastronomic Culture of Colonial Bengal. Cambridge: Cambridge Univ Press.

Sartre, J. P. (2000). Being and Nothingness: An Essay on Phenomenological Ontology (B. I. Koliadko, Trans.). Moscow: Republic. (In Russian).

Shipilov, A. V. (2008). Ours, Strangers and Others. Moscow: Progress-Tradition. (In Russian).

Stringfellow, L., MacLaren, A., Maclean, M., \& O'Gorman, K. (2013). Conceptualizing Taste: Food, Culture and Celebrities. Tourism Management, (37), 77-85. doi: 10.1016/ j.tourman.2012.12.016

Waldenfels, B. (1999). The Other's motive. Mn. (In Russian).

Waldenfels, B. (2002). The Phenomenon of the Other and its Traces in Classical Greek Philosophy. Topos, (2), 4-21. (In Russian). 
Journal of Frontier Studies. 2021. No 3 | ISSN: 2500-0225

Identifying Self and the Other | Doi: https://doi.org/10.46539/jfs.v6i3.322

Yakushenkov, S. N. (2012a). The Image of Alien - from Deconstruction to Construction. Caspian Region: Politics, Economics, Culture, (3), 242-249. (In Russian).

Yakushenkov, S. N. (2012b). The Evolution of the Alien Image in European Vampire Discourse (We'll Put in a Word for the Poor Vampire). Caspian Region: Politics, Economics, Culture, (23), 263-269. (In Russian).

Yakushenkov, S. N., \& Yakushenkova, O. S. (2012). The Body of the Barbarian: Constructing the Image of the Alien on the Chinese Frontier. Caspian Region: Politics, Economics, Culture, (4), 233-240. (In Russian). 